\title{
Beiträge zur mikroskopischen Anatomie des Vogeldarmes.
}

Von

\section{Cloetta.}

Hierzu Tafel XI.

\section{Einleitung.}

Wenn man die Litteratur derjenigen Arbeiten durchmostert, die sich mit der Beschreibung epithelialer Gebilde betissen, so muss es wirklich auffallen, in welch stark hervortretender Weise der Darmkanal stets zum Objecte soleher Arbeiten gewaihlt wnrle. Es mag dies ja wohl mit der unendlichen Wichtigkeit des betreffenden Organs in Zusammenhang stehen, die ja eine möglichst eingehende Kenntniss der versehiedensten Details bei den rersehiedensten Thieren wïnschenswerth macht, um darans allfïllige Winke fiur Verständniss und Erkennung versehicdener Erscheinungen auch am menschlichen Darm zil ziehen, anderseits aber ist es auch die fast unerschöpfliche Vielgestaltigkeit der Bilrter, die uns der Darm unter den verschiedenen Umständen zn liefern vermag, so dass fast bei jeder Untersuchnng sich wieder nene Anschauungen, Yodification oder Verneinung schon bestehender, ergeben. Der Grund nun, weshalb zu nachstehender Arbeit rerade der Vogeldarm gewählt wurde, beruht namentlich darauf, dass über dieses Gebiet speciell noch wenig gearbeitet wurde; wenigstens konnte ich beim Durchmnstern der Litteratur keine Mittheilungen auffinden, die sich in eingehender Weise mit mikroskopischen Verhältnissen des Vogeldarms befasst hätten.

Aber nicht nur geleitet von der Absicht, eine genauere.Beschreibung des Vogeldarms zu geben, ward diese Arbeit begonnen; sondern es erschien auch wünschenswerth einige besondere Theorien und Streitfragen, die sich im Lauf der letzten Zeit herangebildet hatten, an einem nenen Object wieder eingc- 
hend zu prüfen und je nachdem die Basis derselben entweder zn verbreitern oder zu untergraben; ich meine damit speciell die Ansehaunngen Bizzozero's ${ }^{1}$ ) iiber die Regeneration des Darmepithels und Mittheilungen betreffend die Becherzellen.

Gleich zu Anfang iler Untersuchungen stellte sich denn eine Thatsache dar, die wohl mit zu den Hauptgründen zu rechnen ist, weshalb dieses so leicht zu beschaffende und insofern sich für mikroskopische Zwecke wohl eignende Material bis jetzt so wenig Berücksichtigung gefunden hat. Es weist nänlich der Vogeldarm gegeniiber dem vieler anderer Wirbelthiere eine bedentende Kleinheit der zelligen Elemente auf, so dass, um feinere Details hervortreten zu lassen, mit feinen Schnitten und bedentenden Vergrösserungen operirt werden musste. Da uns aber heutzutage beiderlei Mittel zur Verfügung stehen, so ist dieser Umstand als ein die Untersuchungen allerdings erschwerender, aber keinesweg hindermler anzusehen. Gemäss des angeführten Umstandes suchte ich denn auch unter den Vögein diejenigen heransanfinden, die eine möglichst klare Anordnung ibrer zellingen Elemente aufweisen und habe als solches sehr bratuchbares object die Haustaube gefunden.

Was nun die Herstellung des Materials anbelangt, so will ich für Diejenigen, die sich eventuell mit derselben Materie bcschäftigen wollten, einige technische Andentungen geben, um ihnen unnöthige trbeit zu ersparen; denn da über dieses Capitel noch nichts bekannt war, brauchte es oftruals viel Zeit und Mühe fiir die Herstellng brauchbarer Präparate, inden sich eine Reihe von anderwairts ganz gut anschlagenden Agentien hier als unbrauchbar erwiesen.

Sehr za empfehlen ist als Fixirungsmittel eine $3 \%$ Salpetersäurelösung ${ }^{2}$ ), worin der Darm in toto ca. 5 Stunden liegen blieh und tann in gradatim verstärkten Alkokol ubertragen wurde. Hiervon wurden dann kleinere Stücke in Boraxcarmin 24 Stunden durchgefärbt und mit salzsaurem Alkohol ausgezogen. Es liefert diese Methode sehr brauchbare Bilder, wobei namentlich hervor-

1) B i z z o z e r, Ueber die schlauchförmigen Drüsen des Magendarmkanals. Archiv tiir mikrosk. Anatomie Bd. 33, 1889.

2) Stammlösung von spec. Gew. 1,18 (enthält 32\%/0 Säurehydrat) St $\ddot{h}$ h, Lehrbuch der Histologie. 
zuheben ist, dass die zelligen Elemente sehr schön und dentlich in ihrem Contour erhalten bleiben, keinerlei Schrumpfung eintritt, und dass von diesen Objecten äusserst feine Schnitte $(5 \mu)$ angelegt werden können, ohne dass das Epithel abfällt oder sonst Zerreissungen vorkommen. Ein anderer Vortheil ist noeh der, dass man stets den Darm in toto zur Verfügung hat und genau controlliren kann, aus welcher Partie ein fragliches Stück entnommen worden ist. Wenn nun dieses Verfahren für das Contourstudium sehr zweckmässig war, so konnte leider bei complicirteren Färbungen von ilhm kein Gebrauch gemacht werden. Besondere Schwierigkeiten bereitete in dieser Beziehmng das Studium der Becherzellen, wcil keine der schleimfärbenden Substanzen durch Salpetersäure tixirte Präparate, anch dann nicht, wenn die Stiicke nettralisirt worden waren, angriff ${ }^{1}$ ).

Es wurden deshalb Fixirungen mit 10\% Kochsalzsublinatlösung (warm 25-35 Min.), Muller'scher Flüssigkeit und Chromosmium-Essigsäure versucht, von welchen Präparaten dann die Schnitte ungefärbt mit Gummi oder Eiweissglycerin autgeklebt wurden. Derartige Schnitte haben sich als der Schleimfärbungr zngänglich erwiesen. Von den vielen hierfür empfohlenen Mitteln habe ich Vesuvin, Saffranin, Methylenblau und das Delatield'sche Hämatoxylin versucht. Da diese Mittel nicht gleich wirken, und die Resultate hier und da im Veroleich zu anderen Antoren verschieden ansfielen, will ich hier kurz meine Erfahrungen über ihre Wirkung auf den Vogeldarm ausführen. In Bezug auf das Saffranin, das J. P a n e t $h^{2}$ ) sehr rühmt, kann ich die Angaben von $\mathrm{H}$ o y e $\mathrm{r}^{3}$ ) nur bestätigen, dass es ein ziemlich zuverliissiges Mittel sei; ja, hier waren die Erfolge fast ganz negativ. Hoyer hat dagegen hauptsächlich die Vorzüge des Methylenblau hervorgehoben, und kann ich ihm hierin völlig beipflichten, dagegen war

1) A nmerk ung:"Dadurch erklärt sich vielleicht auch die Thatsache, dass der Schleim des Magenepithels sich nicht färben lässt, indem die Unempfindlichkeit dieses Schleimes gegen Farbstoffe, die sonst überall die charakteristische Schleimreaction herbeiführen, durch den Salzsäuregehalt des Magens, wie es scheint, bedingt ist.

2) J. P a n e th, Ueber Darmepithel. Archiv für mikrosk. Anatomie, Bd. 31 .

3) M. Hoyer, Ueber den Nachweís des Mucins in den Geweben mittelst Färbemethode. Archiv für mikrosk. Anatomie, Bd. 36 . 
ich von den Versuchen mit Vesuvin keineswegs so befriedigt wie er; es lieferte undentliche und namentlich inkonstante Färbungen. Ein Vorzug des Nethylenblan, den $\mathrm{H}$ oyer namentlich hervorgehoben, dass es nämlich eine entschiedene Empfindsamkeit gegenüber den qualitativen Verhältnissen des ron den Becherzellen gelieferten Schleimes besitze, konnte ich in vollem Maass bestätigen. Diese Eigenschaft trat namentlich hervor, wenn das Methylenblau in sehr verdünnten Lösungen, ca. $1 / 1000$, einwirkte, doch thut man gut die Färbung, die nach $3-\overline{5}$ Stunden eintritt, unter dem Mikroskop zu überwachen, da nänlich das' übrige Gewebe sich auch mitfärbt, und dadurch eine Differenzirung erschwert wird, da ein nachträgliches, energisches Entfärben des übrigen Gewebes mittelst Alkohol, wegen der bekannten Unbeständigkeit vieler Anilinfarbstoffe gegen Alkohol, die hier besonders deutlich hervortrat, nicht anging. Aus demselben Grunde konnten auch keine Diuerpräparate in Firniss eingeschlossen werden, sondern die Schnitte mussten frisch in Glycerin untersucht werden. Als ganz brillantes Hucinreagens hat sich das Deafieldsche Hämatoxylin ${ }^{1}$ ) erwiesen, das bei den in Chronosmium-Essigsäure gehärteten Präparaten konstant eine selır charakteristische Farbung lieferte, wobei das Gewebe hellbraun, der Schleim dunkelviolett tingirt wurde. Die Reaction tritt bei sehr diluirten Lösungen in 24 Stunden, bei Wischung mit gleichen Theilen Wasser schon in einer halben Stunde auf. Die Hauptrorzinge dieses Mittels bestehen darin, dass eine Ueberfärbung nicht leicht eintritt und die Schnitte alkoholbeständig sind.

Von anderen Färbungen wurden die Methoden von $\mathrm{Her}$ mann ${ }^{2}$ ), so wie die ron $\mathrm{Ehrlich-Biondi}$ und Martin $\mathrm{Hei-}$ denhai n's Häinatoxylin - Eisenlackfärbung ${ }^{3}$ ) versucht, und wird die besondere Wirkung dieser Methoden auf die verschiedenen Gewebstheile an den entsprechenden Stellen erwähnt werden.

1) Taschenbuch der mikrosk. Technik von $B$ öh m and Op pel.

2) Archiv für mikrosk. Anatomie Bd. 34, pag. 60. Das Färbungsverfahren schlägt auch bei Chromosmiun-Essigsäure-Präparaten an.

3) M. H e i d en h a in, Ueber Kern und Protoplasma. Festschrift zu Ehren des כ0jährigen Dr.-Jubiläums von Geh.-Rath v. Kölliker; pag. 118; auch die Ehrlich-Biondi'sehe Firbung wurde nach der von M. Heidenhain (p. 116) angegebenen Modjfication angewendet. 


\begin{abstract}
Allgemeines.
Ueber die makroskopischen Verhältnisse des Vogeldarms verdanken wir $\mathrm{G} a \mathrm{~d}^{\circ} \mathrm{w}^{1}$ ) eine umfassende Beschreibung, in der sich auch einige Bemerkungen speciell über den Darm der Haustaube tinden. Die Länge desselben, vom Pylorus bis zum Anus gemessen, schwankt je nach dem Alter des Thieres zwischen $80-120 \mathrm{~cm}$, seine Wandung ist dünn.' Der Darm stellt in toto einen konischen Schlauch dar; der seine grösste Austehnug am Pylorus, die geringste oberhalb des Inus aufweist, so dass die Querschnitte der betreffenden Partien, wie Cadow angibt, sich im VerhäItniss wic ca. 3:1 bewegen. Die Dnodenalschlinge ist hufeisenförmig gebogen, der absteigende Schenkel ist beträchtlich weiter wie der aufsteigende, ihre Gesammtlange betriggt durchsehnittlich $14-16 \mathrm{~cm}$. Zwischen den beiden Sehenkeln ist das Pankreas eingelagert, dessen Ausführungsgïnge in diesclben einmünden. Der Lebergang tritt ca. $8 \mathrm{~mm}$ vom Pylorts entfernt in den absteigenden Sehenkel ein. Irgend welche Anhaltspunkte für eine makroskopische Eintheilung des Darms bestehen in dessen anatomischer Configuration nicht; er stellt ein vollständig glattes Rohr dar. Dass, wie Gadow bemerkt, die Darmmitte bisweilen unregelmässig erweitert sei, ist mir, obwohl ich anch eine ziemliche Anzahl Tauben secirte, nicht aufgefallen. Die Blindsäieke, die ja bei vielen Vögeln eine ausserordentliche Ausdehnung besitzen, sind hier äusserst mangelhaft entwickelt oder vielmehr zuriickgebililet und stellen eine, ca. $5 \mathrm{~cm}$ oberhalb les Anus befindliche leichte, beidseitige Anschwellung dar. Beim Anfschneiden zeigt sich der Darm meist nur mässig gefüllt, der Inhalt ist in den oberen Partien diunnflussig, gelb oder hellbraun und geht in den unteren Absehnitten in einen griunen Farbenton üher, den man schon durch die Darmwand erkennen kann, und der eigentlich das einzige Merkmal bildet, wonach sich annähernd eine Trennung in Dünndarm und Dickdarm machen lässt; zugleich werden die Massen anch bedeutend consistenter.

Bei Betrachtung der Schleimhaut ergibt sich dieselbe als überall mit Zotten besetzt, die in Duodenum so dicht stehen,

1) Dr. Gadow, "Die Vögel“ in Bronn's Classen und (Irdnungen des Thierreichs.
\end{abstract}


dass die Mucosa, wie Gadow sagt, einen sammtartigen Eindruck macht. Im Dünndarm sind die einzelnen Zotten deutlicher zu unterscheiden, am weitesten stehen sie im Enddarm anseinander und sind derart angeordnet, dass sie beim Auseinanderklappen des Darmes scharfe Zickzack-Längsfalten bilden.

Durchschnitte durch den Darm ergeben, dass auch lier die bei allen Vertebraten bestchende Zusammensetzung aus Schleimhaut, Muskellhant und Serosa vorhanden ist, doch zeigen die beiden ersteren Besonderheiten, die eine eingehendere Beschreibung nothwendig machen.

Die Schleimhaut ist in ihrer ganzen Ausdehnung rom Pylorus bis zum Anus mit Zotten besetzt. Dieselben zeigen in ilhren verschiedenen Dimensionen erhebliche Schwankungen je nach ihrem Sit\%, so dass man wenigstens annähernd bei Betrachtung eines Präparates hiernach entscheiden kann, aus welchen Darmabschnitt dasselbe genommen ist. Bei oberflichlicher Betrachtung glaubt man an den Zotten des Dïmudarms die grösste Länge zu constatiren, doch wird man sich durch Messungen bald üherzeugen können, dass dies nur eine 'Tänschung ist, hervorgebracht durch das wechselnde Verhältniss der Länge- zur Breitendimension 1). Die grösste Ausdelmung besitzen entschieden die Zotten des Duodenum, die cine Länge von 1,0-1,25 mm anfweisen, bei einem Querdurchmesser von ca. $0,16 \mathrm{~mm}$, welche Zall ungeführ der Vitte der Zotten entspricht, während die Basis etwas höhere, bis $0,22 \mathrm{~nm}$, die Spitze entsprechend kleinere, $0,12 \mathrm{~mm}$, Werthe aufweist. Es zeigen also die Zotten des Duodenum meist eine etwas konische Gestalt, was inı Dünndarm weniger der Fall ist, während im Enddarm oft das umgekehrte Verhältniss eintritt. Gegen den Dünndarm zu nelınen die Zotten sowohl in Menge ab, inclem sie weniger dicht beisammen stehen, als auch die Dimensionen der einzelnen, und schwankt dort ihre Länge zwischen $1,0-0,7 \mathrm{~mm}$, ebenso ist auch ihr Durchmesser verringert und zwar, wie schon bemerkt, in erheblicherem Maasse als die Länge; er beträgt zwischen $0,125-0,100 \mathrm{~mm}$. Im Enddarm dagegen sehen wir eine sehr bedeutende Beschränkung im Längenwachsthum bestehen, während der Durchmesser fast gar keine

1) Sämmtliche Messungen beziehen sich auf in Salpetersiure fixirte Präparate, die in Glycerin aufbewahrt wurden. 
Aenderung erleidet, wodurch die Zotten des Dickdarms als die voluminösesten imponiren. Ihre durchschnittliche Länge schwankt zwischen $0,28-0,37 \mathrm{~mm}$, die Dicke zeigt versehiedene Werthe, je nachdem die Messung an der Basis $(0,13 \mathrm{~mm})$ oder an der Kuppe $(0,187 \mathrm{~mm})$ vorgenommen wird. Diese Aenderungen des Durchmessers können, abgesehen von verschiedenen Contractionszuständen, dureh die verschiedenen Componenten der Zotten bedingt sein, und scheint es deshalb angezeigt, die Beziehungen derselben $z u$ einander genauer ins Ange $z u$ fassen. Im Duodenum zeigt auch das Epithel die stärkste Ausbildung $(0,048 \mathrm{~mm})$ und steht zum Zottenstroma durchsehnittlich in einem Verhältniss wie $12: 10-7$. Die Epithelien des Dünndarms sind viederum etwas kürzer, 0,039 mm, und ist hier die Bezielıng zum Zottenstroma eine stets schwankende, indem man Stellen sieht, wo dissselbe beinahe die Stärkc einer Epithellage erreicht, wïhrend es anderwärts kaum 1/3 derselben beträigt. Der Enddarm zeigt eher eine leichte Verorösserung der Epithelien $(0,04)$, während das Stroma bis das Doppelte betragen kann. Eine Verschiedenheit im Durchmesser der Epithelien nach den verschiedenen Darmabschnitten scheint kaum zu bestehen. Es haben diese Zahlen naturlich nur einen relativen Werth, da man den Contractionszustand der Zotten nicht so genau bestimmen kann; die verschiedenen Fixirungsmethoden scheinen keinen wesentlichen Einfluss auf das Epithel zn haben, wenigstens geben Sublimat und Salpetersäure-Lösung annähernd gleiche Resultate.

Bei Betrachtung der Tunica propria fällt die geringe Entwicklung des Bindegewebes auf, das meist nur in geringer Menge zwischen die sehr dicht liegenden Lieberkihn'schen Drüsen eingeschoben ist und nur an denjenigen Stellen, wo grössere Gefässe liegen, in bemerkenswerther Menge vorliegt. Nach aussen von den Lieberkühn'schen Drüsen liegt eine längsverlaufende Muskelschicht, die wir als Muscularis mucosae anspreehen müssen (Fig. 1). Dieselbe zeigt eine ganz ausserordentliche Stärke und ist von der Ringfaserschicht des Muscularis muc. durch eine so geringe Lage von sul)mucösem Gewebe getrennt, dass man fast versucht wäre, sie als selbständige Muskelhaut anzusehen und in Anbetracht der schwach entwickelten (s. u.) änssieren Längsschicht von einer inneren Längs- und äusseren Ringmuskelschicht zu sprechen. Ihre Dicke zeigt eine gewisse Schwankung in den 
verschiedemen Darmabschnitten. Im Duodenum beträgt ihr Durchmesser ca. $0,048 \mathrm{~mm}$, der dann im oberen Theil des Ditnndarms etwas Weniges abnimmt und auf ea. 0,04 nm sinkt, um dann im Aufang des Enddarmes sich wieder etwas zu verbreitern und so, langsam zunehmend, seine grösste Ziffer mit $0,1 \mathrm{~mm}$ oberhalb des Anus erreicht.

Eine ausgebildete Submucosa, die die Schleimlaut von den Muskelhäuten trennte, besteht nirgends; die Muscularis mucosae liegt vielmehr den änsseren Muskelhäuten ziemlich unvermittelt auf, nur durch einige schmale Bindegewebszäge getreunt. Entsprechend dieser geringen Entwickelung finden sich auch nirgends, nicht einmal im Duodenum, Drüsen in ihr eingelagert.

Die Muscularis zerfällt in eine äussere Längs- und innere Ringschicht, die den Darm in seiner ganzen Länge begleiten, hinsichtlich ihrer Dimensionen aber ebenfalls Schwankungen zeigen in den verschiedenen Abschnitten. Im Ganzen ist dic Ringmuskulatur die viel kräftigere, die ihre grösste Ausdehnung im Begim des Duodenum zeigt, wo sie eine Dicke ron ca. 0,37 mm aufweist, während die Längsfasern einen dagegen ganz verschwindenden Durchmesser besitzen. Die innere Schicht nimmt dann schon im Verlauf der Duodenalschlinge merklich ab, noch bedeutender im Dünndarm, in dessen oberstem Theil sie noch einen Durchmesser von ca. $0,14 \mathrm{~mm}$ zeigt, während die Längsmuskulatur sich nicht wenig geändert hat $(0,037)$. Im ganzen Verlauf zeigt sich ungefälu dasselbe Verhalten: eine stete Abnahme der inneren und ein Gleichbleiben oder eher Zunehmen der äusseren Schicht, so dass im untersten Theil des Dünndarms die beiden Muskellagen nahezu einen gleichen Durchmesser von $0,05 \mathrm{~mm}$ besitzen. Im Enddarm nimmt dann, namentlich in dessen unterem Abschnitt, die Ringmuskelschicht wieder zu und erreicht ca. $2 \mathrm{~cm}$ oberhalb des Anus eine Ausdehnung von $0,125 \mathrm{~mm}$, während an der äusseren Schicht kein wesentlicher Wechsel zu verzeichnen wäre.

\section{Feinerer Bau der Zotten.}

a) Epithel.

Die Zotten sind auf ihrer ganzen Oberflache mit Epithel bekleidet, das aus einer einfachen Schicht ziemlich schmaler, 
langer Zellen von hexagonaler Begrenzung und prismatischem Bau besteht. Das Protoplasma zeigt reichliche Körner, die, wem man überhaupt von einer Anorlnung sprechen kann, der Richtung der Zellaxe nach gereiht liegen. Durchaus ungleich ist die Tinktionsfähigkeit des Protoplasma in den verschiedenen Abscbnitten der Zelle und kam man folgendes Verhalten bemerken (Fig. 2): Der peripher vom Kern gegen das Darmlumen gelegene Theil ist in seinen äusseren zwei Drittel intensiv dunkel gefürbt, dann folgt eine hellere Zone gegen den Kern hin, und zwar ist die Trennungslinie zwischen den beiden Farben eine ziemlich scharfe, in leicht concaven Bogen gegen den Kerm hin verlaufende. Im centralen (basalen) Abschnitt beginnt ungefähr in derselben Distanz vom Kern wieder eine dunklere Zone, aber nicht so deutlich ansgesprochen wie die äussere, die gegen die Basis hin leicht abblasst; auch sie zeigt eine leichte concave Begrenzung gegen den Kern, so dass derselbe eigentlich wie in einem hellen Hof eingeschlossen erscheint. Diese Differenzirung ist uamentlich deutlich bei dem Verfahren nach Ehrlich-Biondi, aber anch die Eisenlackpräparate lassen sie ganz gut hervortreten. Nach aussen sind die Epithelzellen durch einen wohlausgebildeten Cuticularsanm abgeschlossen, der lange Stäbchen trïgt.

In dem Zelltheil zwischen Kern und Cuticularsaum hat Nicolas ${ }^{1}$ ) bei Triton, Frosch und Fledermaus Gebilde gesehen, die er als "boules" bezeichnet und die durch verschiedene Farbenreactionen ausgezeichnet waren. Es war mir ummöglich bei der Taube dasselbe zu constatiren, was vielleicht anf Ungunst der Objecte beruht. Dagegen sind die sog. Einschlissse da, ähnlich den von $\mathrm{H}$ eidenh a in ${ }^{2}$ ) beschriebenen, bald über, bald unterhalb des Kern, von verschiedener, oft diejenige des Kern erreichender Grösse; meist sind dieselben rundlich. In den $\mathrm{Eh} \mathrm{r-}$ li ch-B i o n di-Präparaten sind sie intensiv dunkelroth gefärbt, and da bekanntlich zu Grunde gehende Zellen und Reste solcher sich stark tingiren, so ist wohl die Ansicht $\mathrm{H}$ eidenhain's, dass es sich um Reste abgestorbener Zellen handle, die richtige. Heft 1.

1) Intern. Monatsschrift für Anatomie und Physiologie, Bd. VIII,

2) Archiv für die gesammte Physiologie des Menschen und der Thiere, von W. Pfl 1 ü gger, 43. Bd., Supplementheft. 
Die meisten Einschliisse finden sich in den Epithelzellen der Zottenkuppe, doch sind sie anch in denjenigen der Seiten vorhanden.

Ein eigenthïmliches Bild ist mir beim Suchen nach intercellularen Finschlüssen aufgiestossen (Fig. 3). Ein teiner Faden verläuft vom Zottenstroma gegen das Epithel, dort eingedrungeu theilt es sich und scheint mit kugeligen, intensiv gefürbten Knöpfehen zu enden. Das Bild hat mit den von Pfitzue ${ }^{1}$ ) abgebildeten Nervenendigungen im Epithel von Froschlarven eine gewisse Aebnlichkeit. Ich bin aber weit entfernt, dies als wirkliche Nervenendigungen autzufassen, denn es fehlt ein nachweisbarer Zusammenhang des Fadens mit einer zweifellosen Nervenfaser. Auch die Endigung in färbbare Kügelchen ist eine Erscheinung, die an Nervenendigungen nicht bekannt ist.

Der Kern der: Epithelzellen ist oval, nicht immer geenau in der Mitte der Zelle gelegen, sontern meist etwas in die Peripherie verlagert; hesonders bei den schmalen langgestreckten Epithelzellen des Dünnlarms liegen die Leme in ganz ungleicher Höhe, so dass dadureh an dickeren Schnitten ein mehrschichtiges Cylinderepithel vorget:iuscht werden kann. Mitosen feblen.

„Besitzen die Epithelzellen eine selbständige Membran ?"* Mit dieser Frage beginnt He i d e n h a in ${ }^{*}$ ) ein Kapitel, in dessen Verlauf er versucht, den Beweis wesen die Existenz eines solchen zu fülnren. Kölli $\mathrm{ker}^{3}$ ) hat eine solche angegeben, H. Arustein $\left.{ }^{*}\right)$ und $S \in h$ i $f^{*} \mathrm{r}^{5}$ ) haben sich dagegen atsgresprochen. Die Gründe, welche Heide $\mathrm{nhain}$ gegen die Existenz einer Membran ins Feld fithrt, sind folgende:

1) Man sieht Protoplasmabrücken, welche benachbarte Zellen mit einander verbinden. Sind diese Brïcken ohne Weiteres mit wahreu Intercellularbriicken, wie wir sie bei geschichtetem Pflaster-

1) W. Pfitzner, Nervenendigungen im Epithel; Morpholog. Jihrbuch 7.

2) 1 . $\mathrm{c}$.

3) Köllike r, Handbuch der Gewebelehre des Mensehen. Leipzig, 5. Aufl., 1867.

4) H. Arnstein, Virchow's Archiv, Bd. 39.

5) S ch a i e r, on the port played by amoeboid cells in the process of intestinal absorption. Physiolog. Laboratory, miversity collegre, London. Collected papers V. 1885. 
epithel kemnen, za indentificiren? Vergleichen wir beide mitcimander. Der Unterschied ist ein in die Augen springender, wem wir die Abbildun Heidenhain's (Tafel I, Fig. IV) heranziehen. Bei einer Vergrössermg, wie sie in dieser Figur vorliegt, dürften wahre Intercellularbricken überhanpt gar nicht sichtbar sein. Es dürfte îherhunt fraglich seiu, ob die in der Hitte angegebenen Körper alle Stitcken von Epithelzellen entsprechen, ob nicht dabei Bindegewebszellen des Zottenstroma sich betinden. Im Uebrigen ist hier der Vergleich mit wahren Intercellularbrücken schon dadurch völlig ausgeschlossen, dass $\mathrm{He}$ idenhain selbst angibt, dass die dazwischen befindlichen Liicken der Hauptsache nach durch Leukocyten ansgefiillt gewesen sind. Heidenha in ist, indem er anf diese tyenese hinweist, gewiss anch der Meinumg, dass von ächten Intercellnlarbrïcken hier nicht die Rerte sein kïme; denn dariiber besteht ja foch kein Zweifel, dass dicse nicht durch cindringende Lenkocyten gebildet werden. Dic von Heidenhain abgebildeten Protoplasmabrück'n sind also keine wirklichen Intercellularbrïcken. Dass aber diese Druckbilder gexen das Vorhandensein ciner Zellenmembran sprechen, ist nur muter der Voraussetzmar verstandlich, dass ein directer Zusimmenhanow der Zellensalsstanz zweier benachbarter Zellen bestehe. F' it $r$ diesen Znsammenhang soll die Figur IV sprechen, die ich als volles Bewcismittel ans den oben angefïlurten Griunden nicht anerkemen kam, gegon ten Znsammenhang sprechen die vielen mikroskopischen Bilder, die, nach den besten Conservirumgsunethorlen erhalten, bei erwachsenen Zellen stets eine dentliche, oft scharfe Grenze zwischen den benachbarten Zellen zeigen. Ich möchte in dieser Beziehung ant' viele Figuren Heidenhain's selbst verweisen, woselbst die Schärfe der Zellenbegrenzung nichts zu wünschen ibrig lässt. Heidenha in spricht noch ron feinsten Protoplasmabriucken. die in grosser Zahl anch die oberen Enden der Zellen su verbinden scheinen, gibt aber leider keine Abbildung davon, vielleicht waren sie ähnlich den feinen Brücken, welehe $\mathrm{Nicolas} \mathrm{(l.} \mathrm{e.}$ Tafel II Fig. 13) abhildet, und die mit wirklichen Intercellularbrücken iibereinzustimmen scheinen. Auch wir haben an feinen Flächenschitten durch das Epithel der Zottenspitze der Taube etwas tehnliches gefunden, unsere Dentung ist aber eine ganz andere. Fignr ta zeight ein Par soleher Zellenquersehnitte mud 
erseheint als ein Beleg tür die Meinung derjenigen, welche diesen Zellen eine Membran absprechen. Die Ränıler der Querschnitte sind mit unregelmässigen Zacken besetzt, die auf den ersten Blick mit Intercellularbrücken verwechselt werden könnten. Eine genauere Betrachtung, ergiebt jedoch deutliche Unterschiede. Die Zacken sind kur\%, knollig und frei, oft mit leichter Verdickung. Ein Uebertreten rler Zacken bis zur nächstsen Zelle findet überhaupt nicht statt, wir haben hier keine Brücken vor mus, sondern nur Fortsätze. Trot\% aller Aufmerksankeit bei Anwendung bester Systeme (S e ibert homogene Immersion 2 umm) ist es uns nicht gelungen, eine dentliche Verbindung auch nur iihnlich den so leicht constatirbaren wahren Intercellularbricken geschichteten Pflasterepithels walızunehmen ${ }^{1}$ ). Was bedeuten aber jene Zacken? Es sind Protoplasmapartikclehen, welche sich - wohl durch Einwirkung der Reagentien (in mseren Falle Platinchlorid-Osmium-Essigsätue) - voll der Zellmembran etwas aurückgezogen haben, also Kunstprodncte im Feinen, wie es etwa Knorpelzellen in Groben zeigen; der oft sterntörmine Umriss des Knorpelzellenprotoplasma wirl ja bekamtlich dnrch eine ungleichmässige Retraction desselben ron der Innenwand der Knorpelkapsel hervorgerufen. Wir sprechen von einer Zelleumembran; eine solche ist auch dentlich vorhanden, eine leichte Drehung an der Mikrometerschraube bringt sie scharf in Erscheinung; Figur $4 \mathrm{~b}$ ist dieselbe Stelle wie Figur $4 \mathrm{a}$, nur bei etwas anderer Einstelluug gezeichnet. Dass die Membran nicht bei jeder Einstellmo sichtbar ist, erklärt sich wohl, wenn man berücksichtignt, dass hier nicht die ganzen Epithelzellen, sondern un sehr teine (5) $\mu$ ) Quersehuittscheiben derselben vorliegen. Der Membranring, der hier unter dem Präjparat liegt, wirl, so scheint es, etwas überragt vom Protoplasma, dessen zackige Umrandung. hier etwas deutlicher sichtbar ist. Figur $4 \mathrm{c}$ soll zeigen, wie ich mir dies vorstelle. Einstellung aut die Querschnittsflache des Protoplasma wird das Bild der Figur 4a, Einstellumg anf den Querschnitt der Membran wird das Bild Figur 4 b ergeben.

1) Dass zu dicke Schnitte oder Schrägschnitte durch die Epithelzellen Verbindungen vortiuschen können, ist leicht zu begreifen; solche scheinbaren Bricken werien durch Bilder, wie Figur ta auf das zuriickgetïhlut, was sie sind, Täuschmug'en. 
Diese Form des Objectes ist eine Zufälligkeit, und das macht es verständlich, dass man bei vielen anderen Querschnittsbildern bei jeder Einstellung die Membran sieht. Ieh möchte die Frage aufwerfen, ob nicht die verschiedenen Angaben über Intercellnlarbrücken an einfachem Cylinderepithel, wie die ron $\mathrm{N}$ iolas, von $0 \mathrm{~g} n$ e $\mathrm{f}^{-1}$ ) ก. a. nicht anf ihnlichen Präparaten fussen? Gesetat aber, es seien wirklich wahre Intercellularbrücken vorbanden, so liesse sich diese Thatsache nicht als Argument gegen die Zellenmembran anwenden, sobald wir die Insicht $M$ an ile I $\left(1\right.$ e's $\left.^{2}\right)$ aceeptiren, nach welcher dis Lnter(ellularbriteken aus den Membranen der Epithelzellen hervorgehen. Anch nach Ra n vi e r s"s) Untersuchungen schliesst die Existenz einer Zellmembran das Vorhamlensein von Intercellularbricken nicht aus. Die Proto. plasmabrïcken, welcher drt sic anch sein mögen, siml keine vollwichitigen Beweise gegen dis Zellmembran.

2) Wem bei Erhärtung der Schleimhaut die Körper der Zotte schrumpten, riehen sich die unteren Enden der Zellen in lange dünne Protoplasmatortsätze aus. Anch riese sollen nach H e iden ha in der Anwesenheit einer das Protoplasma einhïllenden Membran willersprechen. Es ist zweifellos, dass die mteren Enden der Zellen oft ungebogen sind und von der nächst abwärtsgelegenen Zelle gedeckt werlen. Man muss in dieser Form den Effect der rom Drisengrund herant erfolgenden Verschiebung der Zellen erblicken. Aber es ist wohl ebenso sicher, dass diese kleinen "schuppenförmigen" Fortsätze von den oben genannten langen Fortsützen gestaltlich sehr verschieden sind; wir erblicken in Let\%teren ein Kunstproduct und stimmen darin

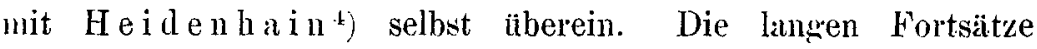
diirften bei dem Streit un die Zellmembran wenig brauchbar sein.

Diesen, wie es mir scheint, wenig schwerwiegenden Argumenten gegen die Existenz einer Zellmembran stehen, abgesehen von meiner obigen Schildernng, eine Reihe direkter Beobachtungen gegenüber: Die Epithelzellen der Zotten werlen ant'Zusat\% von Wasser rund, eime deutliche Membran hebt sich rom Proto-

1) $O \mathrm{~g}$ n e f $\mathrm{f}$, Biologisches Centralblatt 1892.

2) M a nile I d e, la muqueuse des cellules du corps muquenx de Malpighi. La cellule. Tome 4. 1888, eitirt nach Nicolas l. c.

3) R invier, Journal de Micrographie 1891, pang. 171.

4) l. c. latg. 21 . 
plasma der Zelle ${ }^{1}$. H e i d e n h a i u hat diese Membran als eine Folge der Einwirkung des Wassers auf die Albuminate der Zelle, als 'Traube'sche Niederschlagsmembran erklärt. Wenn dem so ist, duirfte wohl zu erwarten sein, dass älmliche Membranen auch bei andern Zellen \%. З. Driisenzelleu auftreten. Davon ist nichts bekannt, selbst $\mathrm{H}$ e i (le en ha in ${ }^{2}$ ), ller die Zellen von Eiweissund anderen Driisen unter Zusatz der versehiedensten Reagentien untersucht hat, erwähnt keiner derartigen Erscheinung. Indererseits ist die Zellunembran nicht nur auf Zusat\% ron Wasser oder sehr verdünnten Salzlösmugen, sondern auch bei Einwirkung anderer Reagentien, die sehwerlich Traube sehe Niederschlassmembranen hervormfen, nachzuweisen. An Sublimatpräparaten sicht man oft deutlich, dass die zwischen zwei Epithelzellen herablantende Grenzlinie aus zwei Streifen zusammengesetzt ist (Fig. 2). Besonders instructiv erscheinen Präparate, an denen sich das Protoplasna ler Zellen etwas contrahirt hat, dort hat sich die leicht geschlängelte Membran abgehoben und ist unschwer als ein selbständiges Gebilde zu demonstriren.

Als weiteres Beweismittel für die Membran kömnten wir dic Becherzellen heranzichen, denen selbst $H$ eiden hain, wenigstens all den Seitenfluchen eine Membran znerkennt. Da aber die Frage, ob die Becherzellen aus gewïhnlichen Epithelzellen hervorgegangen sind. - das ist ja die jetzt herrschende Meinung, - noch nicht völlig entschieden ist, müge auf dieses Hültsmittel verzichtet werden. Tch bin also der Meinung, dass die Zottenepithclzellen eine Membran besitzen, nnd erachte diese Meinung durch die vorstehende Erörterung hinreichend begründet.

I)ie Epithelzellen enden stets glatt abgeschlossen gegen den Zottenkörper hin, ein Zusanımenhang zrischen ihnen und dem Zottenstroma, wie er früher vielfach beschrieben und abgebildet wurde, besteht nicht.

Vielfach scbon sind bei Abbildungen von Epithelzellen unter den normal tingirten Zellen intensiver getärbte abgebildet worden. Auch in den schon mehrfach erwähnten Arbeiten von

1) Kölliker, Handhuch der Gewebelehre 5. Aufl. 1867, pag. 409 und 412.

2) Heidenhain, Harmann, Handbuch der Physiologie, Bici. V, pag. 18. 
Heidenhain und $\mathrm{Ni}$ colas finden sich solche. Bei Heidenh a in sind die Zellen in ihrer ganzen Ausdehnung dunkler gefärbt, auch Kern und Kernkürperchen treten intensiver hervor; die Zellen stehen im Niveau der anderen, scheinen aber doch etwas schmäler zn sein und zeigen einen Cuticularsaum. Bei Nicolas finden sich ähnliche Abbildungen, auch lassen riese Zellen stellenveise deutliche Beziehungen zu Bechersellen erkennen. Anch bei der Taube trifft man zahlreiche dieser dunklen Zellen an; auch hier sind sie schmäler, intensiv gefürbt, dis oben erwähnte lifferenzirung des Protoplasma ist verschwunden, und der Kern hat sich bei den Ehrli ch-Bi o n d i-Präiparaten tief grün-blau gefärbt. Derartige Zellen finden sich überall an den Zotten, an deu Seitentliachen sowohl wie an der Spitze, anch in ten Liebcrkühn'schen Krypten kommen sie vor. Die Cmstände, nuter denen sie entstehen können, sind verschieden. Als die erste Ursache müssen Faltungen des Epithels, hervorgerufen durch Contraction der Zotte, bezeichnet werden (vergleiche auch die Figur 9 S pee's $\left.{ }^{1}\right)$, in anderen Fiallen sind es die vergrösserten Becherzellen, welche ihre Nachbarn 'm solehen dunklen Zellen umgestalten; in den Lieberkühn'schen Drüsen sind die dort häufigen Mitosen als firnere Ursache leicht zu erkemnen (Fig. o), in wieder anderen Fillen, nud das betrifft die Spitze der Zotten, ist es offenbar der von beiden seiten her wirkende Wachsthums. druck der von den Krypten heranfriickenden Epithelzellen. Dieser Letztere wirkt am besten anf alte Zellen, anf Becherzellen, tlie ihr Secret abgegeben haben, man sieht oft dentlich, dass solche dunkeln Zellen an ihrem freien Ende noch einen Rest von Schleim enthalten. Auch $\mathrm{Nicolas^{2 } )}$ bildet solche Zellen ab. So verschieden anch die ursächlichen Momente sind, der Effect ist stets der Gleiche, die Compression. Ich betrachte also die dunkeln Epithelzellen als comprimirte Elemente. Die Frage, welche von diesen Zellen unter die absterbenden Elemente zu zählen sind, habe ich nicht näher untersucht; ich möchte aber glauben, dass gerade die an der Zottenspit\% vorkommenden dahin gehören. Es ist überhaupt auffällig, wie oft die Zottenspitzen

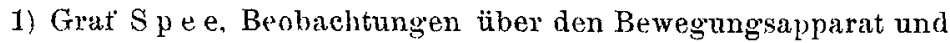
die Bewegungen der Dirmzotten sowie deren Berleutung fiur den ChyIusstrom. Habilitationsschrift tür Kiel 1885.

2) Nicolas, l. c. Figur 20 . 
Läsionen des Epithels aufweisen. Wenn wir annelmmen, dass dort die ältesten, am wenigsten widerstandisfähigen Zellen liegen, - die Berechtigung hierzu wird weiter unten erörtert, - so finden wir vielleicht damit die Erklärung für die eigenthümlichen Bilder Grün hayens $\left.{ }^{1}\right)$. Was $G r$ ï $n$ h a a Oeffnungen hält, "durch welche das sattuetz der bindegewebigen Zottenpapille direkt ohme Vermittlung des Zottenepithels mit dem Darmchyums in Verkehr treten kïnnte", ist ein Kunstprodnet, bedingt durch die dort betindlichen altersschwachen Zellen.

b) stroma (Zot tenkïruer).

Das Zottenstronna setzt sich zusammen aus Muskelfasern and aus Bindegewehe mit vielen zelligen Elementen, welehes der Träger der Blut- und Lymplogefässe der Zotte ist. Ich vermacr darüber verhiiltnissmässiö nur weuig mitzutheilen. Die Muskelfasern sind in \&en Zotten der Taube ziemlich zahlroich vorhauden, nehmen ihren Ursprung in der kräftigen Hnseularis mucosae, von wo aus zwischen den Lieberkühm'schen Drüsen Bündel hinaufsteigen, die wich theils zu dickeren Stämmen verbinden. theils sich in einzelnen Fasern spalten, oder auch mintereinander Biindel anstauschen. $M a l^{2}$ ) gibt an, dass beim Hunde die Zottenmuskehn nicht von der Muscnlaris mucosae ansgehen, sondern ohne Zusammenhang mit letzterer höher oben in der Tunica propria liegen. Ich muss dem für die Taube anf das Bestimmteste widersprechen; man sieht deutlich, wio sich Fasermüge von der Muscularis mucosae abzweigen und senkrecht zwisehen den Krypten in die Zotten autsteigen (Fig. 1). Vou der Basis der Zotte riehen daun die Muskelstränge in gerader Richtung nach aufwärts. In Beaug auf ihre Vertheilnng erwähnt $\mathrm{M}$ a 11 bein Hunde 2 Lagen, eine äussere sehwächere und eine innere stärkere; ein ähnliches Verhalten scheint bei der Taube vormuliegen, indem um den centralen Chylusranm meist 2-4 dickere Muskelstränge liegren, während mehr nach aussen zahbreichere, abes diünnere Stränge Fig. 9.

1) Grünhagen, Archiv tür mikrosk. Anat. Bd. 29 pag. 145,

2) Mall, Die Blut- und Lymphwege im Dünndarm des Hundes. Abhandl. d. mathem.- physikal. Klasse der Kol. saichs. Gesellschat't der Wissenschatten Bd. XIX, Nr. III, 1887 pag. 179. 
vorhanden sind. Die Anordnung ist natürlich variabel nach der Höhe der Zotten, indem auf Zottenquerschnitten sich das ziemlich einleuchtende Verhältniss bestätigt, dass unten die Buindel sparsamer und dicker, oben zahlreicher und dünner sind. Auf ihrem Weg geben die Bündel zahlreiche Fasern ab, aber nicht in der Weise, dass diese unter rechtem Winkel nach aussen abstehen, so dass quere Verbindungen bestänlen, sondern mehr in schräger Richtung nach oben. Nach der Zottenspitze zu worden die Muskelzïge immer schmäler und kann man sie bis fast unter die Zottenkuppe verfolgen, allwo nur noch einzelne Fasem bestehen, deren Endverhalten, il. h. ob mehr bogentïrmig and sehlingenbildend, wie dies Spe e ${ }^{1}$ ) beschrieben, oder ob mehr gerade und trei endigend, mir unmöglich war zu erkennen.

Das zwischen den einzelnen Muskelfasern befindliche Bindegewebe ist an den schmalen Zotten nur in geringem Grade vorhanden. Besser ausgebildet ist es an den breiten Zotten. des Enddarmes.

Der äussere Contour der Zotte wird durch die sog. Basalmembran oder, wite $\mathrm{He}$ ide $\mathrm{n}$ h a in sie nemt, die subepitheliale Grenzschicht", grebildet und verstehen wir mit ihm darunter diejenige Zone, die nach innen von den Blntgefüssen, nach anssen vom Epithel begrenzt ist. Schon mehrmals ist die Provenien\% dieser Sehicht diskutirt worden, ob es sich um eine selbständige Membran handle, oder ob sie, wie $\mathrm{He}$ id e $n$ h a in annimmt, als ein Bestandtheil des Zottenkörpers zu betrachten sei. Das dichter angeordnete Bindegewebe des Randes hebt sich hier und da etwas distincter vom Zottenkörper ab, wodurch eine wirkliche Membran vorgetäuscht wird; aher man sieht so vielfach innige Verbindungen mit dem unterliegenden Bindlegewebe, dass die Meinung Heidenhain's auch fïr die Taube geltend erklärt werden muss.

Was die Zellen des Zottenstroma's anbelangt, so hat $\mathrm{He} \mathrm{i-}$ denhain ${ }^{2}$ ) folgende Arten aufgestellt:

1) die gewöhnlichen Wanderzellen,

2) die sogenannten sesshaften Zellen, specifisch nicht verschieden von den Wanderzellen, sondern nur einen anderen

1) l. c. pag. 159 .

2) Heidenhain, l. e. pag. 37-44. 
functionellen Zustand darstellend. Beide sichtbar bei Hämatoxylin- und Alaunkarmin-Färbung.

Bei Anwendung der Ehrlich-B iondi'sehen Methorle unterscheidet er

3) noch 4 weitere Irten:

a) Zellen mit kleinem, fast farblosen Protoplasmaleibe,

h) mit grösserem, hell rosa gefärbtem Protoplasma,

c) mit farblosem Protoplasma, in welches intensiv dunkel roth gefärbte Körnchen dichter oder zerstreuter eingelagert sind;

(1) Zellen, deren Kern kleiner, intensiv dunkel blangriin gefäirbt, deren späricheres oder reichlicheres Protoplasma intensiv dunkelroth tingirt ist. I efunde :

Bei unseren Untersuchungen ergeben sich hierzu folgende

An Schnitten von mit Boraxkarmin durchgetärbten stücken sielit man in dem Stroma eine riemliche Menge von Zellen eingelagert, deren Protoplasma gar nicht, deren Kerne dunkelroth gefälbt sind und die nichts anderes als die gewölnlichen Leukocyten darstellen, die, wie $\mathrm{He}$ id enhai in um Hoy e ${ }^{-1}$ ) schon hervorgehoben, das Gros der zelligen Elemente in der Zotte bilden. Namentlich hüibsch präsentiren sich die Kerne an Präiparaten in Chront-Osmium-Essigsäure gehärtet mo nach $\mathrm{H}$ e rmann tingirt, wobei man folgende zwei Arten unterscheiden kann:

1) Kleine Zellen mit ehromatinreichem polymorphem Kern.

2) Etwas grïssere Zellen mit bläschenförnigem Kern und einem oder mehreren Kernkörperchen, die wohl den von Heidenhain als sesshaften beschriebenen an die Seite zu stellen wären. Was die Färbung nach Ehrlich-Biondi anbelangt, so muss ich bemerken, dass meine Erwartungen hierüber nicht ganz gerechtfertigt wurden, indem hierbei keineswegs sehr klare und hübsche Bilder geschaften wurden, trotzdem ich die Färbung an Präparaten in Sublimat gehärtet, mit oder ohne Zusatz von Kochsalz, und mit verschieden langer Einwirkungsdauer versuchte. Der Kern der Leukocyten erscheint diffus blau, das Protoplasma röthlich gefärbt. Zellen, deren Protoplasma gefärbte

1) Hoyer, Beitrag zur Kenntniss der Lymphdrüsen, Archiv für mikrosk. Anat., Bd. 34 . 
Körnchen einschliesst, habe ich trot/s aller diuranf hiugewendeten Autmerksamkeit nicht finden können.

\section{Die Lieberkühu'schen Krypten.}

Was die Druisen des Tanbendarmes anbelangt, so existirt in remsclben nur cine Art, die Lieberkühn'schen Drüsen, während die Brunner'schen Druisen im Duodenum, wie übrigens hekamntlich bei allen Vögeln, fehlen. Die Lieberkühn'schen Krypten finden sich in ter ganzen Lïng'e des Dams, stellen einfache Blindsäcke dar, olune gabelige Spaltung. Was die Länge fler Drïsen nach den verschiedenen Darmabschitten betriffit, so ergeben sich riemlich geringe Differenzen, sollass keine so deutlichen Merkmale bestehen fïr das Erkemen des Damnstitckes wie an den Zotten. Dic bedeutendste Länge besitzen sie im Duodenum, ea. $0,20 \mathrm{~mm}$, im Dëmmlarm nehmen sie etwas ab, noch mehr im Begimn des Enddarmes, während sic im untern Theil des Enddarmes wieder zn erheblicherer Längre (ca. 0,19) ansgebildet simt. Was das Lumen dre Krypten anbelangt, so bestehen ebenfalls keine wesentlichen Ibifferenzen.

Die Drisen sind in sämmtlichen Darmpartien von einem cinfachen Cylinderepithel ansgekleidet. dessen Zellen nur minime Wechsel in Bezng anf ihre Dimensionen antweisen und finden sich dementsprechend im Duodenum Werthe von 0,024 , im Dünnclarm 0,02, im Enddarm wieder ähnlich wie im Duodenum. Es resultirt aus diesen Zahlen im Vergleich mit den Epithelien der Zotte (s. o.), dass die Drisenepithelien bedentend kleiner sind, eine Thatsache, die ja ibbrigens schon bei ciner Reihe anderer Thiere constatirt wurde.

Das Protoplasma der Epithelien zeigt ebenfalls eine feinkïrnige Tusammensetzung, tingilt sich gleichtalls rosa bei der Ehrlich-Biondi-Fürbumg, aber doch nicht so entschieden, wie das Zottenepithel. Anch hier ist dentlich der gegen das Lumen gokehrte Theil etwas intensiver gefärbt, nur ist die betreffende Zone etwas schmäler als beim Zottenepithel; und ebenso zeigt das centrale Ende oftmals eine etwas stärkere Imbibition, so dass ich in dieser Beziehung Paneth' ${ }^{1}$ ) nicht ganz beistimmen kann,

1) Paneth, Ceber Darmepithel. Archiv rïr mikrosk. Anat. Bd. 31, faig. 174 . 
wenn er den Drüsenepithelien jeden Tinctionsunterschied abspricht.

Vom Zottenepithel senkt sich der Cuticularsaum auch in die Krypten hinab, doch zeigt sich dabei eine zumehmend schwäichere Entwicklung, so dass man den auf der Zotte kräftig. entwickelten Saum im Fundus der Driisen fast aus dem Gesicht verliert. Paneth hat bei seinen Untersuchungen an der Maus diese Erscheinumg ebenfalls betont, ja, er stellt sogar die Anwesenheit eines wirklichen Cuticnlarsaumes in den Krypten wïnzlich in Abrede, indem er sagt, dass er sich nur noch ,als homogene Linie fortsetze, an der nicht eimmal mehr eine Qnerstreifung $\pi$ erkennen sei." Dieser Angabe kann ich mit Bezug auf meine Untersuchungen nicht ganz beipflichten; lem wem auch ein deutliches Schwäicherwerden vorhanden ist, so scheint dies doch melır in einer Verkleinermy der Stäbehen zu liegren. Es ist allerdings richtig, ich habe den Saum nicht allerorts in den Krypten nachweisen können, aber an einzelnen Orten besteht er in soleher Dentlichkeit, dass man an seiner Existenz nicht wweifeln kann. Zn einem ähnlichen Resultat kommt Heirlenhain, wenn er auch den Cuticularsaum der Krypten nicht als vïllig irlentisch annimmt mit dem der Zotten. In Bezug auf die Kerne der Kryptenepithelien ist zu bemerken, dass sie mehr in dem basalen Theil der Zelle liegren, und da dort die Zelle breiter ist, - eine nothwendige Folge ihrer Anpassung an die Umgebung (vergleiche das umgekehrte Verhalten der Zottenepithelien) 一, so hängt wohl auch rlamit ihre mehr rundliche Form zusammen. In der Grösse scheinen zwischen ihnen und denjenigen der Zottenepithelien keine merklichen Unterschiede zu bestehen, dagegen farrben sie sich etwas intensiver. Intercellulare Einschluisse habe ich in den Druisenepithelien uur sehr wenig. gesehen, auch die Leukocyten, die zwischen dem Zottenepithel sich oft so zahlreich finden, sind hier spärlicher.

In Uebereinstimnung mit den Berichten Bizzozeros ${ }^{1}$ ) kommen bei der Taube Kerntheilungsfiguren auch nur in den Krypten vor: und zwar in der ganzen Krypte zerstreut liegend, vom Grunde bis zum Hals, in reicher Anzahl, - man kaun auf einem Schnitt bis 6 und mehr Mitosen sehen (Fig. 1). Zu ihrem

1) Bi\%zกz(ro, Archiv tür mikrosk. Anatomie, Bł. 333. 
Nachweis reicht jede reine Kenufärbung bei passender Fixirung ans $\left.{ }^{1}\right)$. Die Mitosen liegen stets in den dem Lmnen zugekehrten Theil der Zellen, ihre Theilungssebene steht senkrecht zum Kryptenlumen. Differenzen in ihrer Zahl oder in sonstigem Verhalten nach den rerschiedenen Darmalsschnitten sind mir nicht autgefallen. Was die Bedentung dieser Kerntheilungen betrifft, so dürfte als feststehend anzumehmen scin, dass sie nichts mit der Secretion zn thm haben. Schon Heidenhain hat nachgewiesen, dass weder Hungern noch grute Ernahrumg bei Hunden an der Häutigkeit dieser Kerntheilungsfiguren etwas andert, und auch wir sind bei der Taube zn demselben Resultat gekonmen; ebenso haben sich Pilocarpin-Injectionen als gänzlich einflusslos erwiesen. Die Kerntheilungen dienen also mur der Ernenerung und fragt es sich licrbei nur wessen? Nehmen wir an. die Mitosen dienen nur zum Ersatz der zu Grunde gehenden Kryptenzcllen, so bleiben uns zmr Erklärung des entsprechenden Vorgangres anf den Zotten nur zwoi Wege übrig: Entweder die Zottenepithelien gehen überhaupt uicht zu Grumle. - eine Ammahme, die wohl von keinem der neneren Forscher gebilligt wïrde, - oder für die zn Grunde wehenlen Zellen mnss ein anderer Ersatzmodus bestehen. Mit dieser letzteren . unnahme fünden wir uns in Einklang. mit Frentze197, welcher bei Untersuchungen uber die Epithelregeneration des Mitteldarmes bei Insekten zu dem Sehlusse kommt, dass die eigentlichen Epithelzellen, gleichviel ob sie dem Darmschlauch oder auch dessen Ausstiilpungen angebören, sich durch Amitose, die specitischen Drüsenzellen der Krypten dagegen Inrch Mitose fortpflanzen; es ist auffallig, dass diese Angaben so vielfach citirt werden, auffällig, weil eine eingehendere Präfung lie Berechtigung solcher Angaben in sehr zweifelhaftem Lichte erscheinen lässt. Ich vermag wenigstens, Bildern, wie Bd. 26 Taf. VIII Fig. 26a u. Taf. I Fig.24a, absolut keine Beweiskraft für amitotische Vorgänge zuzuerkennen. Wo diese jungen Zellen iiberhaupt herkamen, ist gar nicht gesagt; die Thatsache, lass die Kerne

1) Anuerkung: Auch bei Huhm, Heise, Amsel und Sperling besteht das greiche Verhalten.

2) Frentzel, Ueber den Darmkanal der Crustaceen nebst Bemerkungen zur Epithelregeneration. Archiv rïr mikrosk. Anat. Bd. 25 und .Finiges über den Mittellarm der Insekten, sowie üher Epithelregeneration". Ebenda Bd. 26. 
dieser Zellen nur den vierten Theil, bei anderen nur den neunten Theil der Grösse der Kerne der alten Zellen besitzen, spricht wenig für die Identitit der jungen Zellen und der ausgewachsenen Epithelzellen. In Uebricen spricht die Mehrzahl unserer jetzigen Ertahrungen einer lebenstähigen Zellproduction auf amitotischem Wege clurehnus nicht das Wort. All diese Unklarheit fällt weg, sobald wir amehmen, lass die Vitosen auch zum Ersatz des Zottenepithels dienen. Hiermit stossen wir aber bei Heidenhain und Paneth ${ }^{1}$ ) anf Widerstand, indem Beide ras Zottenepithel als nicht identiseh mit dem Kryptenepithel annehmen. Ho ide uh a in hebt zum Beleg hierfïr im Einzehen folgende Befunde hervor:

1. bestehen hedentende 'Tinctionsunterschicde,

2. finden sich nirgends auf den Zotten den sog. Körnchenxellen entsprechende Gobilke, Zellen, die zuerst Panetb im Fundus der Driisen bei vielen Thieren gesehen und deren Vorkommen anch von $\mathrm{He}$ ide uha in und Nicolas bestätigt wurde,

3. Unterschiede im Cuticularsamm.

Dass durch rliese Differenzen, die von uns im Vorausgebenden ebentalls \%. ' $\mathrm{T}$. bemerkt wurlen, z einer: völligen Trennumg der beiden Zellarten der Grund gelegot sein soll, künnen wir um so weniger acceptiren, als die Amahme"), dass die Zellen der Krypten die Jumgen, jene der Zotten die Nlten darstellen, mu vieles plansibler erscheint unl diese Differenzen einfach als Altersdifferenzen zu erklären wären. Es wäre nit dieser Annalune auch eine rollkommen logische Erweiterung der Bizzozero'schen Theorie gegeben.

\section{Lymphknötchen.}

Umschriebene Ansammlungen von Lymphkörperchen fehlen auch im Darn der Taube nicht. Allertings sind diese Knötchen nicht sehr zahlreich unt vielfach solitär. Wirkliche Plaqnes scheinen zn fehlen. Wie wir wissen ${ }^{3}$ ) entstehen die Lymphkü̈t-

1) s. v. I. c.

2) Vergleiche Stöhr, „Ueber das Darmepithel“. Ergebnisse dre Anatomie und Fntwiekelungsgeschichte, Wiesbaden 1892.

3) Stiohr, Ueber die lymphknötchen des Darno's. Archiv tïl mikrosk. Anat., Ba. 3s. 1489. 
chen des Darmes in der Tunica propria und in den angrenzenden Theilen der Submucosa - ihr weiteres Wachsthum vollzieht sich aber vorzugsweise in dem in der Submuensa gelegenen Theil, der damit sum Hauptkörper des Knötchens wird. Das fertige Knötchen der Säuger ist also mit seinem griissten Theile in der Submucosa grelegen. Das oben erwähte Fehleu einer eigentlichen Submueosa im Vogeldarmbedingt eine ganz andere Form der Knötchen. Sie liegen fast aussehliesslich in der Tnnica propria ${ }^{1}$ ) und sind ron einer Höhe, die der einer Zotte nicht viel nachgibt, man kömnte solche Lin̈tchen geradezi mit Leukocyten gefïllte Zotten nennen, eine Auffassung, die mit unseren diesbezüglichen entwickelungsgeschichtlichen Erfahrungen wohl äbereinstimmt. Dass die Tentenz einer Ansbreitung nach unten anch hier hesteht, geht daraus hervor, lass der basale, hauptsächlich vom Keimeentrum gebildete, Theil des Knötchens die Mnsenlaris mucosac durchbrochen und noch eine deutliche Delle in der Ringmuskulatur verursacht hat (Fig. 1). Anf Querschnitten habe ich meist nur ein Knötchen getroffen; es lay in der Nähe des Mesenterialansatzes, aber ein solches Knötchen enthiclt, wie aus der Betrachtung der Serie hervorgeht, mehrere von einander getrennte Keincentra; ein Längsschnitt kïmite also wohl das Bild ciner Reihe neben einander gelegener Knötchen, eine Art von Plaque, ergeben. Wirkliche Längsschnitte durch solche Knötchen besitze ich nicht. Zusammensetzung, Epithelbekleidung 11. s. w. der Lymphknötehen zeigt clie bekannten Verhältnisse.

ther anch in Bezug auf Nerven und Blutgefüsse ist das Fehlen der Submucosa von Einfluss. Es ist unmöglich hier zwei getrennte Plexus zn constatiren; die an ihren bläschenförmigen Kernen leicht erkenularen Ganglienzellen liegen z. Th. zwischen Ringmuskelschichte und muscularis mucosae; sie entsprechen demnach Elementen des Meissner'schen Plexus, zum andern Theil finden wir Ganglienzellengrrppen sowohl zwischen Längs- und Ringmuskelschichte, als anch in Letzterer selbst.

Bekanntlich lösen sich im Allgemeinen đlie Blutgefässe des Darmes, nachdem sie die Musknlaris durchsetzt haben, gewöhn-

1) Beim Hahn lagen die Knötchen pux in ter Tunica propria und warem nach unten von der nudurchbrochenen museularis mucosac brogrent. 
lich in zwei der Fläche nach ansgebreitete Netze anf dliesseits and jenseits der muscularis mneosae. Bei der 'Taube muss sich biertïir eine dem anatomischen Verłalten der Schichten entspreehende Aenderung ergeben. Die grösseren Gefäisse durchsetzen quer die Ringmuskelschicht, zu deren Eruährung sie vorher ein reichliches arterielles Flächcmetz abgegeben haben; da nun eine Ausbreitung in der Submuensa nicht möglich ist, so tudelen wir in der Tunica propria noch relativ grosse Gefässe, die regelmässig in den Septen zwischen dem Fundus der Lieberkiilmschen Krypten liegen, von wo damn die Zottengetässe an den Seiten der Drüsen, rereint mit den Wuskelbündeh in lie Höhe steigen.

\section{Becherzellen.}

Es ist nicht meine Absicht, den sich so vielfach wietlerInolenden Beschreibungen iiber Form und Structur der Becherzollen eine weitere hinzuzutügen, - ich habe in dieser Hinsicht nichts wesentlich Neues zn berichten - ich möchte vichnehr die Aufmerksamkeit anf einen bisher fast völlig veruachliissigten Punkt lenken, nämlich auf die Topographie der Becherzellenstadien.

Zum Nachweis jeder Becher\%elle, sowohl der in den ersten Stadien der Schleimbililung bexriffenen, wie der his auf einen kleinsten Rest ihres Secretes entledigten, bedarf' es der Anwendung eines schleimfürbenden Reagens. Die eleganteste Färbung habe ich mit Delafield'schem Hämatoxylin er\%ielt, das, ant" mit Flemming's Gemisch fixirten Präparaten applicirt, den Vorzug hat, dass es ausschliesslich den Schleim - sonst nichts - intensiv färbt und so auch kleinste Spuren von Schleim leicht entilecken lässt. Dabei ist die Färbung danerhaft, die zum Theil schon vor einem Jahr angefertigten Präparate haben sich bis jetzt nicht im Nindesten verändert.

Beginnen wir mit der Schildermg der Topographie der Becherzellenstadien im Enddarm, weil dieselbe hier an Klarsten vorliegt.

Becherrellen in den Krypten. Es sind hier sehr feine Längsselunitte nöthig, tie genau die Mitte des Drisenlumein getroffen haben. Die dicht gerlouingten Epithel\%cllen, ihre radiär 
zum Lumen gerichtete Stellung, bringen es mit sich, dass vielfach Tangential- und Schrägselınitte selbst bei ten besten Prïparaten mit unterlaufen, die bei der Beobachtung sorgfältig ansgeschaltet werden müssen, will man nicht $\%$ falschen Schlüssen gelangen. Die meisten Becher\%ellen, die in der niichsten Nïhe des Kryptengrundes stehen, sind schlanke, die Dicke gewöhnlicher Epithelzellen nicht iibertreffenle Gebilde, bei denen der schleimige $\mathrm{Ab}$ sehnitt, der häutig nicht sehr intensiv gefürbt ist, zwei Drittel bis drei Viertel der ganzen Zellenlänge eimimut (Figur $b$ a). Weiter gegen die Kryptemüindung zu ist der schleimige Absehnitt etwas mehr ausgebaucht (b) und intensiver gefärlot, doch tindet man anch vereinzelte Bccherzellen, die von dersellon schlanken Gestalt sind, wie die oben beschriebenen tieferen Zellen. Im Kryptengrumde selbst sind neben den sehlanken Becher\%ellen einige, die durch die Ansbanchung ihres Lumenabschnittes sich. auszeichnen $\left(b^{\prime}\right)$. In der Mehrzahl der Fälle simd die Becherzollen nicht rlicht nebeneinander gelegen, somilem ilurch 1-4 gewöhnliche Epithelzellen getrenut.

Becherzellen a uf den Zotten. An der Grenze zwischen Krypten- und Zottenepithel ist ein anfiallender Wechsel der Gestalt der Becherzellen zu constatiren. Die Becherzellen des Zottenepithels sind wieder viel schlanker geworden, das Längenverhältniss zwischen schleimigem und protoplasmatischem Abschnitt hat sich zu Gunsten des letzteren derart verschoben, lass entweder beide gleich lang oder der protoplasmatische Abschnitt sogar etwas länger ist (Fig. $7 \mathrm{c}$ ). Dieser Gestaltswechsel lässt sich ungezwungen auf mechanische Einflüsse zurückfuilıren; tlas gesammte Epithel unterliegt von dem Augenblicke an, da es das Lumen der Krypte überschritten hat, nicht mehr dem tort herrschenden Drucke. Dort bildet es die innere Auskleidung einer Röhre, deren Inhalt auf die Zellen einen Druck ausübte; hier auf der Zotte stellt es die Ueberkleidung eines Kegels dar, der Druck hat mit einem Male aufgehört, die Streckung der Epithelien ist das Resultat dieses Nachlassens ${ }^{1}$ ). Es ist leicht einzusehen, wie unter solchen Unuständen die Zelle h (Fig. 7) sich zur

1) In merk $u n g$ : Als zweiter Faktor kommt selbstrerstandlich der durch die in den Krypten immer neuwahseman Zellan ansgeübte Wachsthumrnek rou moten her in Betracht. 
Form c umgestalten kann; die Umgestaltung trifft hauptsächlich den anpassungstähigen, protoplasmatischen Abschnitt, er ist bedeutend länger geworden, der in b runde Kern hat in c eine oblonge, parallel der Zellen-Längsaxe gerichtete Gestalt angenonmen. Allmähliche Uebergänge führen zu Formen, die etwa in der Mitte der Zottenhöhe sich finden. Der schleimige Abschnitt, intensiv gefärbt, hat sich auf Kosten des protoplasmatischen Theiles stark ausgedehnt, er nimmt gut drei Viertel der Zellenlänge ein (Fig. $8 \mathrm{~d}$ ). Von da ab ist eine allmähliche Abnahme des schleimigen Abschnittes zu constatiren, dieser Theil verliert gleichzeitig an Breite (Fig. $8 \mathrm{e}$ ); an der Zottenspitze selbst erkennt man die Becherzellen nur mehr mit Mühe, sie sind zu ganz schmalen strichförmigen Gebilden geworden, an deren freiem Ende noch ein kleiner, tief dunkelblauer Zapfen sitzt, der letzte Rest von Schleim (Fig. 8 f). Nicht selten ist die Epitheloberflüche über solchen leeren Becher\%ellen zu einem kleinen Grübchen eingezogen. Auch auf den Zotten sind die Becherzellen nicht nebeneinander gelegen, sondern durch mehrere (zwischen 1-6) gewöhnliche Epithelzellen getrennt.

Bezüglich der Stellung der Becherzellen im Epithel der Duodenalschlinge und des anschliessenden Dünndarms kann ich mich kürzer fassen, da die Verhältnisse im Wesentlichen die gleichen sind wie im Enddarm. Auch in den Lieberkühn'schen Krypten dieser Darmabschnitte finden sich Becherzellen, aber ihr Vorkommen ist ein sehr wechselndes, neben Krypten, die gar keine Becherzellen enthalten, finden sich - an ein und demselben Quersclnitt der Darmwand - Krypten mit einzelnen und Krypten mit vielen Becherzellen, welch letztere sich wie diejenigen der Enddarm-Krypten verhalten.

An der Zottenoberfläche liegen die Becherzellen in mehr unregelmässigen Distanzen, indem die Zahl der dazwischen eingeschalteten gewöhnlichen Epithelzellen von 2-12 und mehr schwankt. Aber auch hier ergibt sich, dass die verschiedenen Stadien nicht regellos nebeneinanderliegen, sondern die jüngeren Stadien entfernter, die älteren Stadien näher der Zottenspitze liegen. Es kommen Varianten vor und zwar in der Weise, dass an der einen Zotte die im Maximum ihrer Secretfïlllung befindlichen Becherzellen der Spitze, an der anderen Zotte der Basis näher gerückt stehen, das gegenseitige Lageverhältniss der ein- 
zelnen Stadien wird dadurch nicht alterirt. Der Grund dieser Differenz liegt vermuthlich in den Zahlen der Mitosen, die bald schnelleren, bald langsameren Nachschub aus den Krypten zur Folge haben. Dagegen kommt es nicht vor, dass frühe Becherzellenstadien an der Spitze und ältere an der Basis derselben Zotte gelegen wären. Die Constatirung dieser Thatsache ist nicht so leicht wie im Enddarm; die Schwierigkeit steigert sich mit zunehmender Länge der Zotte und damit zunehmender Seltenheit eines genauen Lïngsschnittes; man muss sich eben hüten, Schrägschnitte von Zotten für Spitzen zu halten und Tangentialschnitte von Becherzellen für Anfangs- oder Endstadien der Secretion anzusprechen. Das sind indessen Gefahren, die nur bei der ersten oberflächlichen Betrachtung bestehen; der nur einigermaassen darin Geübte wirl solche Verwechslungen zu meiden wissen.

Es ergibt sich ans vorstehender Beschreibung, dass die Becherzellenstadien nicht regellos durchcinander, sondern in gesetzmässiger Reihenfolge liegen. Ich werde kaum auf Widerspruch stossen, wenn ich die zu Seiten des Kryptengrundes befindlichen schlanken Becherzellen als jüngste, die strichfömigen Becherzellen (Fig. 8 f.) der Zottenspitze als älteste Form erkläre. Beide, Anfungs- und Endstadien, sind durch zahlreiche Uebergänge mit einander verbunden. Wir dürfen also sagen, dass die Becherzelle, indem sie reift, ans der Krypte, dem Orte ihrer Geburt, in die Höhe rückt bis zur Zottenspitze, woselbst sie untergeht. Und rlamit findet die Annahme Bizzozero's, dass die Elemente des Darmepithels aus den Lieberkiuhnschen Krypten stammen, eine Unterstïtzung. Aber es bestehen doch einige Punkte, die in scheinbarem Widerspruch stehen. Est ist Regel, dass die jungen Becherzellenstadien tiefer (d. h. der muscularis mucosae näher) stehen als die älteren. Ich habe keinen Fall gefunden, in dem zwischen prallgefülten Becherzellen eine völlig entleerte gelegen war, wohl aber, wo noch eine prallgefüllte Becherzelle mitten in einer Gruppe halb geleerter Zellen sich befand; derartige Fälle erklären sich ungezwungen aus der Thatsache, dass ja die Neubildung der Epithelzellen nicht nur im Grunde der Krypten, sondern in ihrer ganzen Länge bis zum Halse herauf vor sich geht (vergl. pag. 107). Es ist also leicht verständlich, dass einzelne höher gelegene 
Zellen etwas jünger sein können - sie müssen von Mitosen im Drüsenhals stammen, - als andere tiefer gelegene; die Differenz wirl aber nur eine geringe, entsprechend der geringen Entfernung des Kryptengrundes vom Kryptenhalse, sein. Ein anderer Punkt bietet grössere Schwierigkeiten: Wie erklïren sich die grösseren Becherzellen (Fig. 6b) im Kryptengrunde selbst? Sind dieselben auf günstigere mechanische Umstände zurtickzufülıren? Ich glanbe kaum. Meiner Meinung nach sind sie durch die Verschiebungen zu erkläiren, welche durch die mitotischen Processe herbeigefïhrt werden. W'enn sich eine Epithelzelle theilt, werden durch die zwei jungen Zellen die Nachbarn zur Seite gedrängt; im Allgemeinen wird diese Versehiebung nach anfwärts in ler Richtung gegen das Kryptenlumen erfolgen. Und dass die Verschiebung wirklich in dieser Richtung stattfindet, dafür spricht, abgesehen von den oben angezogenen Beweisgründen, die newerdings von $\mathrm{Bizz0ze0^{1 }}$ ) betonte Form der Epithel. yellen; sie sind mit ihrer Convexität uach anfwärts gegen das Kryptenlumen gekehrt. Aber es ist durchaus nicht ausgeschlossen, dass zeitweise auch - natiurlich nur kleine - Verschiebungen in umgekehrter Richtung erfolgen. Sieht man doch anch Epithelzellen in gerade umgekehrter Stellung die Convexitait abwärts kehrend! Dass solche Verschiebungen durch Mitosen verursacht werden, dafür diene als Beleg Figur 5 . Es könnte also sein, dass eine kleine Auzahl von Zellen abwärts gegen den Kryptengrund gedrängt wird und dort auch bleibt. Denn die in der Nachbarschaft auftretenden Mitosen werden sie geradezu an dieser Stelle festhalten können. Es ist also leicht möglich, dass dort im Grunde ältere Zellen liegen und die verhältnissmässig grossen Becherzellen daselbst sprechen dafür. Diese Auffassung scheint mir auch für die Erklärung der von $\mathrm{P}$ a neth und nach ihm von $\mathrm{N}$ i colas beschriebenen Körnchenzellen verwendet werden zu können. Wir haben oben gesehen, dass an der Spitze der Zotten, wo Zellen zu Grunde gehen müssen, häufig Körner in den Zellen gefunden werden. Sollten die körnerhaltigen $\mathrm{Pa}$ neth'schen Zellen nicht auch alte, zu Grunde gehende Zellen sein? Ich stehe mit dieser Auffassung freilich nicht in Einklang.

1) Bizzozero, Archiv für milsrosk. Anat., Bd. 40. Eine eingehende Berücksichtigung dieser Arbeit war mir nicht mehr möglich. 
mit der kürzlich von Bizzozero gegebenen Deutung, nach welcher die Panctlischen Zellen nur die jugendlichen Formen von Schleimzellen sind. Aber ich glaube, dass die bedeutende Grösse ler Paneth'schen Zellen dieser Auffassung wenig günstig ist. Beträgt doch ihr Querdurchmesser nahe\%u das Doppelte einer Becherzelle, die wir sonst für eine jugendliche zu balten allen Grund haben ${ }^{1}$ ). Ich bin nicht in der Lage meine Auffassung weiter begründen zu kömen, denu bei der Taube habe ich im Kryptengrunde keine Zellen gefunden, die vollkommen mit den von $P$ a $n$ e th beschriebenen Formen übereingestimmt hätten. Vor allem misslang der dentliche Nachweis ron Körnchen ${ }^{2}$ ).

Ein weiterer Punkt möge hier noch kurz beruhhrt werden. Bei einer jungen Taube habe ich in der ganzen Länge der Zotten prallgefüllte Becherzellen getunden, ein direkter Widerspruch mit dem bisher Geschilderten ist damit nicht gegeben, denn es bestand ja keine Regellosigkeit in der Reihenfolge der Stadien.

Die topographische Untersuchung der Becherzellenstadien führt also $x u$ dem Ergebniss, das im ganzen D a rm, v on Pylorus bis zur Hündung des Enddarmes, die Becherzellenstadien in gesetzmäsiger Reihentolge liegen, und zwar in der Weise, dass die älteren Stadien stets höher (den Zottenspitzen näher) gelegen sind, als die jüngeren Stadien. Die Consequenzen sind einschneidende und bedingen zum Theil eine Aenderung unserer bisherigen Auffassung.

Znerst liegt in dieser Beobachtung eine weitere Bestätigung der Ansicht Bizzozero's, dass die Regeneration der Darmepithelien durch Heraufrücken der Elemente aus den Lieberkühn'schen Krypten erfolgt.

Zweitens sind wir erst jetzt in der sicheren Lage, die ersten Secretionsstadien der Becherzellen von Endstadien zu unterscheiden. Es ist zweifellos, dass viele bisher gelieferten Beschreibungen des Secretionscyclus auf Irrthümern beruhen, weil

1) Vgl Bizzozero's Frgm. 1 der Tafel 19.

2) Ich habe aber dort Zellen gesehen, die sich durch helles Aussehen, durch ihre verhältnissmïssig bedeutende Grösse von den Nachbarzellen auszeichnen. 
die Zusammenstellung der Reihenfolge eine willkürliche war. Man wird jetzt mit mehr Aussicht auf Erfolg an die Untersuchung der ersten Schleimbildung herantreten können, die um so wïnschenswerther ist, als einige der bisherigen Angaben sehr auffallend sind ${ }^{1}$ ).

Drittens - md das ist das wichtigste Resultat - wird unsere bisherige Anschamung, dass die Becherzellen öfter Schleim billen und ansstossen kömen - einstweilen für die Tambe haltlos; dem wenn eine Becherzelle mehrmals Secret bilden kïnnte, müssten wir anch an der Zottenspitze junge Stadien finden.

Damit ist durchans nicht ausgeschlossen, dass die Becherzellen gleich ron Intang an in den Krypten schon sccemiren, dass kaum gebildeter Schleim alsbald ausgestossen wird. Aber die Schleimbildung gelıt rascher vor sich als die Schleimabstossung; so kommt es, das der Grad der Füllung einer Becherzelle stetig zunimmt bis zu einem gewissen Punkte. Von da ah überwiegt dic Schleimausstossung, bis zur Zottenspit\%e ist damn die Becherzelle bis anf unbedentende Reste leer und geht diann wahrscheinlich zu Grunde. Für diese Annahmen bietet der oft schon in den Kryptenlumina befindliche Schleim den Beweis.

ob dic Becherzellen wirklich specifische, von den gewöhnlichen Epithclzellen verschiedene Elemente sind - wie Bizzozero meint - darüber wage ich kein Urtheil; die so überaus wechselnde Anzahl der Becherzellen scheint mir einer solchen Auffassnng wenig günstig.

Fassen wir die in Vorstehendem eingehend geschilderten Resultate meiner Untersuchung zusammen, so ergibt sich Folgendes:

1) Die Darmwand der Taube, des Huhns, der Amsel, der Meisen und des Sperlings besitzt eine mächtige muscularis mucosae, entbehrt einer Submucosa. Die bei andern Thieren daselbst gelegenen Organe sind in Nachbarschichten gedrängt, die Lymphknötchen und ein Theil der Blutgefässe sind in die Tunica pro-

1) Vergl. Lukjanow, Grundzüge einer allg. Pathologie der Zelle. Leipzig 1891. Steinhaus, Ueber Becherzellen im Dünndarmepithel der Salamandra maculosa. Arch. von D ubois-Reym ond, 1888 
pria, ein anderer Theil der Blutgefüsse und die Nervengeflechte theilweise in die Ringmuskelschicht gelagert.

2) Die reifen Epithelzellen der Darmobertläche besitzen eine Membran; wahre Intercellularbrïcken fehlen.

3) Mitosen der Epithelzellen kommen auch bei Vögeln nur in den Lieberkühn'schen Krypten und zwar in deren ganzer Lünge vor.

4) In der ganzen Länge des Darmes sind die Becherzellen gesetzmässig nach dem Grad ihrer Secrettiullung vertheilt, die jüngsten Stadien liegen in der Tiefe, die älteren in der Höhe (den Zottenspitzen näher). Daraus ergibt sich, dass die Becherzellen nur einmal secerniren.

5) Aus den beiden letrtgenamnten Resultaten (3 und 4) ergibt sich eine nene Bestätigung der Lehre Bizzozero's, dass die Neubildung rer Epithelzellen nur von den Lieberkiühn'schen Krypten aus stattfindet und dass die auf der Höhe der Zotten befindlichen Zellen aus den Krypten heranfocwanderte Elemente sind.

Angelangt an Schlusse der Arbeit, bleibt mir noch die an-

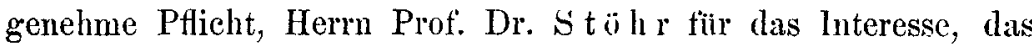
er dieser Arbeit gegenüber gezeigt, sowie tïr die vielen Opter an Mühe und Zeit, die er deren Ausführung dargebracht, meinen herzlichsten Dank auszusprechen. Seiner Hand verdanke ich die beistehenden Abbildungen.

\section{Erklärung der Figuren auf Tafel XI.}

Sämmtliche Figuren stammen von der Taube und sind mit einem Zeichenprisma entworfen. Alle Abbildungen sind naturgetreu, keine Schemata (mit Ausnahme der Figur 4c).

Fig. 1. Stück eines Querschnittes durch den Dünndarm. Flemm. Flüssigkeit. Saffranin. Seibert Objectiv 00 Comp. Oc. 12.

Fig. 2. Zottenepithel des Dünndarms. Sublimat. Ehrlich-Biondi-Flüssigk. Homogene Inmers. $2 \mathrm{~mm}$ Comp. Oc. 6. 
Fig. 3. Zottenepithel des Dünndarms. Flemm. Flüssigk. Hermann's Färbung. Homogene Immers. Comp. Oc 4.

Fig. 4. Querschnitt von Epithelzellen einer Dünndarmzotte. Hermann's Flüssigk. Flomogene Immers. Oc. 8.

Fig. อ̆-9. Stammen von Prïparaten, die in Flemming's Flüissigkeit fixirt und mit Delatield's Hamatoxylin gefirbt worden waren.

Fig. 5. Längsschnitt einer Lieberkühn'schen Krypte aus dem Enddarm. Seibert Apochromat $8 \mathrm{~mm}$ Comp. Oc. 18.

Fig. 6. Desgleichen.

Fig. 7. Längsschnitt tiner Kryptenmündung, aus dem Enddarm. Vergr. wie 5 .

Fig. 8. Stück eines Lïngsschnittes durch eine Zottenspitze des Enddarmes. Verror. wie 5.

Fig. 9. Senkrechter Schnitt durch die Schleimhaut des Enddarmes.

Fig. 10. Senkrechter Schnitt durch die Schleimhaut des Dünndarms. Hermann's Flüssigk. Delafield's Hiimatoxylin. Seibert Apochromat $8 \mathrm{~mm}$ Comp. Oc. 6.

\section{Beiträge zur Lehre von der Fortpflanzung und Vererbung. \\ Von}

\section{Yussbanm.}

In der Abhandlung, Zur Differenzirung des Geschlechts im 'Thierreich (Archiv für mikroskopische Anatomic 1880), begründete ich eine Reihe von Vorstellungen, die sich aus der Entwicklungsgeschichte der Geschlechtsorgane und dem Vorgang der Conjugation und Befruchtung ergaben.

Dem weiteren Ausbau meiner Theorie habe ich mit einer Reihe jüngerer Arbeitsgenossen seit jener Zeit den grössten Theil meiner wissenschaftlichen Bestrebungen gewidmet. Auch von anderer Seite ist in den folgenden Jahren ein Theil der in jenen Arbeiten ausgesprochenen Gedanken durch neue Entdeckungen bestätigt worden und hat sich vielseitig Anhänger erworben. Ein anderer 'Theil aber wird auch heute noch von einer nicht 